\title{
ESTUDIOS
}

\section{Budismo y Humanismo}

\author{
Fernando Tola y Carmen Dragonetti \\ Fundación Instituto de Estudios Budistas FIFB, Argentina \\ The Bubbist Association of the United States
}

$$
\text { \& }
$$

\section{Resumen}

El estudio se inicia con el reconocimiento de la capacidad humana para conocer su entomo. Trata, luego, de la importancia del conocimiento en el Budismo en tanto reflexión filasófica. Se abordan también los aportes del Budismo a la formación cultural del hombre latinoamericano a partir de conceptos como apertura mental, racionalidad y tolerancia, asociados a nuestra realidad. El artículo se cierra con un recuento de los principios filasóficos y las valores éticos del Budismo.

Palabras claves: Budismo, filosofía india, éticaludista.

\section{Abstract:}

The purpose of this paper is to present the importance of knowledge in Budism as a philosophical reflexion. The author also refers to Budism as a factor for the cultural development of Latinoamericans. Concepts like mental openness, rationality and tolerance in close relation to our reality are discussed.

Key words: Budism, indian philasophy, budist ethics.

\section{Ell hombre, un ser nacidb para aprender}

$7^{1}$ hombre no es sólo un ser nacido para vivir en sociedad, como HAristóteles dice, es también un ser nacido para adquirir, transmitir y acumular conocimiento. Desde que apareció sobre la tierra, el hombre estuvo condenado a aprender y a enseñar. Tuvo que aprender a encender 
el fuego para cocinar sus al imentos, calentarse en el inviemo, ahuyentar a los animales malignos; tuvo que aprender a construirse un refugio que lo protegiera de las inclemencias del tiempo y de las acechanzas de la selva y de la noche; tuvo que aprender a procurarse pieles que cubrieran su cuerpo, a fabricarse herramientas y armas para defenderse de los animales que le disputaban los espacios de la sobrevivencia y del poder. Tuvo que aprender a convivir con otros seres semejantes a él, a fijar los límites de lo que podía hacer y no hacer, a establecer jerarquías, respetos y obediencias. Después descubrió o inventó el mundo de los dioses, de los demonios, de todos los seres sobrenaturales que habitaban en su imaginación o en la inmensidad del espacio, en las alturas del cielo, en las profundidades del agua, en la espesura de los bosques. Y tuvo que aprender a manejarse con ellos, a tratarlos, a ganarse su buena voluntad o a aplacar sus iras. Éstas y otras muchas innumerables cosas tuvo que aprender para sobrevivir y para echar los fundamentos de la cultura, que sin saber y sin querer iba creando y aún hoy, con nuestras culturas bien establecidas aunque maltrechas, no pasa un momento en que no tengamos que aprender algo, que las sin cesar cambiantes condiciones sociales, económicas y políticas del mundo, el constante avance de las técnicas, y el incremento siempre mayor de las comunicaciones, imponen a nuestras mentes.

Y por ascuros instintos de sobrevivencia de la especie o por confusas sentimientos de afecto o por sensata valoración de los conocimientos cuya eficacia había experimentado, aprendió a transmitir los conocimientos que adquiría a compañeros, a hijos, a discípulos, que a su vez los transmitían a otros en una sucesión de maestros cuyo origen se pierde en el tiempo.

Y los conocimientos se acumulaban, por ininterrumpida transmisión de generación en generación, por obra de cualquiera, por obra también de expertos en el arte de mantener en su memoria lo que a ella le canfiaban.

Fue primero una transmisión oral, de boca a oído, pero luego el hombre inventó la escritura. Y fue poniendo por escrito todo el conocimiento adquirido, transmitido y acumulado por su generación y las generaciones anteriores: códigos de conducta, tratados sobre los ritos con que se venera a los dioses o se marcan las etapas de la vida, 
textos sobre la forma de curar, de construir, de pelear, de hacer el amor, de educar, etc. Y se reunieron bibliotecas, en las que se atesoraba lo aprendido y se aseguraba su transmisión a las generaciones futuras.

Toob este conocimiento estaba originariamente marcado por el signo del utilitarismo. Eran conocimientos útiles, que para algo servían, fundamentalmente para la sobrevivencia, para la conservación de la vida en un mundo cruel y despiadado, al cual el hombre había llegado desnudo, desarmado e ignorante, para hacer esa vida más tolerable y satisfactoria, para enriquecerla con algún tipo de experiencias agradables.

Pero, cuando las circunstancias se hicieron más benignas y el hombre se sintió menos apremiado por los requerimientos de la sobrevivencia, surgió en él la tendencia a adquirir , transmitir y acumular conocimiento sin finalidad ulterior, sin beneficios irmediatos: conocer por conocer.

La actividad de la mente que quiere conocer por conocer puede aplicarse a variados dbjetivos: seres, cosas, hechos, actos, procesos, con el fin de inventariarlos, establecer su naturaleza, descubrir sus causas, determinar las leyes que los rigen. Esta actividad puede ser superficial o profunda, acotada o amplia, y puede dar mayor o menor importancia a uno u otro de los fines señalados.

Es corriente oír decir que aquello que entendemos por « filosofía griega» es una disciplina intelectual que se caracteriza por buscar el saber puro, que tiene en sí misma su razón de ser, que se agota en la actividad que la constituye.

Se afirma también que por ser así una actividad puramente intelectual, a la aul nada extraño al intelecto se le agrega, la «fil losofía griega» es una de las creaciones más eximias del hombre, digna sólo de la cultura griega, que en la Antigüedad sería la única depasitaria de la razón.

Pero además de la pureza que se le atriburye a la actividad filosófica griega, se saca un argumento en contra de la filosofía india. Se arguye que los sistemas filosóficos de la India no son ejercicios de la razón pura, que siempre tienen en mira algún resultado diferente de la mera actividad de la mente, y que, por no buscar el conocimiento por el conocimiento, la filosofía de la India no sólo es un prooucto inferior al griego, sino que incluso ni siquiera merece ser llamada «filosofía». 


\section{ㅍ. La finalidad del conocimiento en la India}

Desde luego, la mayor parte de las afirmaciones que anteceden son discutibles. Lo que sí podemos considerar como cierto es que la India adoptó, en relación al conocimiento, una actitud muy diferente: consideró básicamente que toda disciplina intelectual no constituye una búsqueda del saber por el saber y no tuvo el menor reparo en aceptar que toda actividad racional pretende alcanzar algún bien extemo a esa actividad, ajeno a ella, superior a ella.

La posición india en el ámbito hindú está claramente expresada en el Nyäyadarsana (Ciencia de la Lógica), en el sütra I, l de Gautama. Gautama afirma que del «conocimiento de la verdadera naturaleza» de las 16 categorías lógicas se produce la «obtención del supremo bien».

De acuerdo con lo expresado por Vatsyayana, Uddyotakara y Vacaspati Misra en relación con este sütra, debemos entender que la expresión «conocimiento de la verdadera naturaleza o de la verdadera realidad» se refiere, en cada ciencia, a un dbjeto específico propio de cada ciencia. En la ciencia de la lógica, el objeto, cuya verdadera naturaleza es necesario conocer, está constituido por las 16 categorías lógicas, pero debe tenerse muy en cuenta que el ätman (principio espiritual individual) forma parte de una de esas categorías (prameya) . Además, en la ciencia de la lógica, lo que se obtiene mediante el indicado conocimiento es el supremo Bien, que no es otra cosa que la liberación de las reencamaciones.

El comentario de Vatsyayana relativo a este tema es el siguiente: «Hay que saber de acuerdo con la Doctrina que el conocimiento de la verdadera naturaleza [de las casas] es con el fin de alcanzar el supremo Bien. Pero aquí en la doctrina del Ätman [alma] el conocimiento de la verdadera naturaleza [de las cosas] es el conocimiento del Ätman, y de los otros objetos. La obtención del supremo Bien es la consecución de la Liberación».

El värttika de Uddyotakara ad locum es my explícito y claro: «En todas las Ciencias hay 'conocimiento de la verdadera naturaleza' y 'obtención del supremo bien' . ¿Qué es 'conocimiento de la verdadera naturaleza' y 'obtención del supremo bien' en la Ciencia de los Vedas? 'Conocimiento de la verdadera naturaleza' es el conocimiento de los implementos apropiados y adecuados para el (rito) Agnihotra, etc. 
'Obtención del supremo bien' es la obtención del Cielo, pues en los Vedas se dice que el cielo es el resultado (de los ritos). En la Ciencia de la Agricultura, ¿qué es 'conocimiento de la verdadera naturaleza' y 'obtención del supremo bien' ? 'Conocimiento de la verdadera naturaleza' es el conocimiento de la tierra -que no está afectada por espinas, etc., tal es el conocimiento de la verdadera naturaleza (de la tierra) . Y 'obtención del supremo bien' es la obtención de la cosecha. En la Ciencia de la Política ¿qué es 'conocimiento de la verdadera naturaleza' y 'obtención del supremo bien'? La utilización de la conciliación, de los regalos, del castigo, de crear disensiones, según el momento, el lugar y la capacidad (de hacerlo), es el 'conocimiento de la verdadera naturaleza' y 'obtención del supremo bien' es la conquista delatienrà.

\section{Importancia del conocimiento en el Budismo}

Pasemos al terreno budista. Señalamos en primer lugar que desde sus inicios el Budismo tuvo una alta valoración del conocimiento, que designó con los términos jäñana, en sánscrito (= ñaña, en páli) y prajñä, en sánscrito (= pañ̃nä, en pälì) . El acto que inició la carrera de Gotama como Buda fue un acto de conocimiento: la Iluminación (bodhl) , la manifestación más excelsa del conocimiento, de la Inteligencia, de la Conciencia, en que la realidad se presenta en su absoluta totalidad ante la mente de aquel que con inauditos esfuerzos logró capacitarse para esa experiencia suprema. El hecho de que la palabra Buddha (Buda), «El que despertó a la verdad», «El Iluminado», «El que conociós, sea utilizada desde ese momento con respecto a Gotama para expresar la perfección y la superioridad que lo elevan por sobre todos los seres, es indicativo del lugar preeminente que el conocimiento ocupa en la escala budista de valores. La avidiyä, justamente lo contrario del conocimiento, es considerada por el Budismo, como la raíz de todos los males, que debe ser destruida, al igual y más aún que las pemiciosas tendencias y proclividades, conscientes $\mathrm{O}$ inconscientes, a hacer el mal y a transgredir las normas de la Ética. A tal punto el Budismo Mahäyäna valorizó el conocimiento constituido por la Iluminación, que en los sütras mahäyänistas lo que Buda les profetiza a sus Bodhisattvas, como logro 
supremo de sus esfuerzos, prácticas y méritos, es que llegarán a ser Buddhas, es decir, que serán poseedores de aquel conocimiento que ubica al que lo pasee en el plano trascendente de los seres superiores, teniéndose por tal razón la impresión que el Mahayana más que una religión del Nirväna, es una religión de la Boohi (Iluminación) , del conocimiento en su forma más intensa y pura. Además, el conocimiento de la verdadera naturaleza de las cosas, de la verdad de la realidad, que constituye la Perfección del conocimiento (prajñapiiramitaj y que está centrado en la idea de la Vaciedad, es decir de la Insustancialidad Universal, es una condición indispensable, un requisito ineludible para aquel que ingresa en el camino salvífico que enseña el Budismo. Y sin este conocimiento no es posible realizar, en su plenitud y entera eficacia, la Disciplina Moral, centrada en el desapego y en el sentimiento de la compasión universal -Disciplina Moral que constituye, junto con el conocimiento, la otra condición indispensable, el otro requisito ineludible para el éxito del esfuerzo budista.

Por eso, desde sus primeras épocas los budistas como comunidad se esforzaron por llegar al conocimiento de la verdadera naturaleza de las cosas. Fue una búsqueda afanosa y constante a partir de las intuiciones geniales de Shäkyamuni, que quedó plasmada en audaces y grandiosos sistemas filosóficos. Ias escuelas se sucedieron, indagando cada una por sí misma, matizando, armando los resultados alcanzados por sus predecesores. Se abrieron sin cesar nuevos ámbitos para la reflexión, se recorrieron caminos desconocidos en la investigación. Todas las sectas y escuelas, en que el Budismo se dividió como efecto de su intensa vida espiritual e intelectual, participaron en esa búsqueda y contribuyeron a la promoción, profundización y diversificación del conocimiento.

\section{El pensamiento budista como reflexión filosófica}

El pensamiento budista fue en gran parte una reflexión de neto corte filosófico, llevada a cabo mediante el análisis racional. Las circunstancias históricas doligaban a los pensadores budistas a ubicarse en un terreno exclusivamente lógico. Los pensadores budistas, en efecto, se enfrentaron durante muchos siglos a los pensadores hindúes, que 
sostenían tesis consagradas por una larga tradición, como al margen de toda duda y controversia. Los budistas no podían hacer valer, en defensa de las tesis revolucionarias que aducían -insustancialidad de toob, inexistencia de Dios (iovara) , inexistencia del alma (âtman) textos que expresaban la palabra de Buda, la cual para los hindúes no poseía autoridad alguna. Se veían así obligados a recurrir a argumentos de razón y a constituir sólidos fundamentos racionales para las doctrinas que propugnaban.

La función preeminente, que en el Budismo tuvo la reflexión racional filosófica, no impidió que conjuntamente con ésta se valorara y practicara la meditación yóguica (dhyyâna), no sólo como práctica que serena la mente, liberándola de emociones y pasiones e incrementando así su eficacia funcional, sino como otro camino o método del conocimiento, que, colaborando con el estudio de los textos y la reflexión fi losófica sobre las doctrinas que éstos enseñan, permite llegar a una captación más cabal, de naturaleza intuitiva, de la verdad.

\section{1. La finalidad del conocimiento en el Budismo}

A pesar de la alta valoración que le concede, el Budismo tiene frente al conocimiento la misma actitud que la del Hinduismo. El conocimiento no tiene en sí mismo su propio fin, sirve para obtener algo no sólo extemo a él y diferente de él, sino algo superior a él. El budista se esfuerza por alcanzar el grado máximo del conocimiento, la Iluminación, para convertirse en un Buddha, en un «Iluminado» dotado de eximias cualidades y atributos, que tendrá su mundo de Buda, Buddhaksetra, concebido como un magnífico paraíso, donde guiará a millones de seres hacia la Iluminación, durante millones de períodos cósmicos, realizando en esa forma una obra de compasión, para finalmente ingresar, cuando él lo decida, en el Parinirvâna supremo y sin retomo, que, cercano o lejano, ha sido siempre la última meta del camino budista. El conocimiento es un simple medio, un mero sâdhana, al igual que la Disciplina Mbral.

De entre las dos indicadas actitudes frente al conocimiento, ¿cuál elegiremos los latinoamericanos en relación al estudio del Budismo? ¿Estudiaremos el Budismo únicamente con el afán de conocer por 
conocer o realizaremos ese estudio con una finalidad que esté más allá de la simple acumulación de conocimiento? Y en este último caso, ¿cuál es esa finalidad? Creemos que en el estudio del Budismo ambas actitudes pueden estar presentes, armoniosamente entrelazadas.

\section{2. El Budismo camo campo para el conocer por el conocer}

El Budismo ofrece un amplio campo para el ejercicio del conocer por el conocer. Se extendió por vastas regiones del Asia: India, Sri Ianka, Sudeste Asiático, Tibet, Asia central, China, Mongolia, Korea, Japán, que en muchos momentos estuvieron al frente de la civilización humana. Subsistió en esas regiones durante siglos. Ejerció su influencia sobre la historia y la cultura de numerosos pueblos, formuló sistemas filosóficos, dio origen a manifestaciones de intensa vida religiosa, produjo obras literarias, inspiró escuelas de arte. Y lo que el Budismo prooujo en los distintos campos en que incursionó se caracterizó, en general, por su riqueza, por su variedad, por su .profundidad y por el interés que suscita. Utilizó múltiples idiomas para la transmisión de sus doctrinas. Son inmumerables los filósofos, artistas, escritores, hombres santos que lo representaron. El Budismo ofrece así un rico tesoro de hechos por inventariar, analizar, conectar entre sí, explicar, de idiomas por describir e interpretar, de textos por editar y traducir. Nunca el Budismo dejará de proporcionar al historiador, filólogo, antropólogo, arqueólogo y demás cultores del conocimiento, interesante y valiosa materia para sus investigaciones, curiosidades, inquietudes.

Io que ya se ha hecho bajo la inspiración del conocer por el conocer, es enorme. Japoneses, indios, europeos, americanos, chinos, koreanos, tibetanos, etc. , han realizado una labor admirable de enudición, capaz de competir en cantidad y calidad con aquella realizada en el campo de los Estudios Clásicos Greco-latinos. Han acumulado y estudiado una masa inmensa de datos, han descifrado idiomas, han establecido textos confiables y rigurosos de las obras budistas. Queda aún mucho por hacer. Los latinoamericanos podemos asociarnos, aunque sea en forma modesta, a esa tarea. 


\section{3. El Budismo camo fuerza espiritual}

Pero el Budismo es también una poderosa fuerza espiritual, que ha ejercidb y ejerce una inresistible atracción. Inaulca en el individo actitudes positivas; formula como explicación de la realidad en que existimos, principios profundos, que sorprenden por su adecuación a la experiencia que el hombre tiene de esa realidad, y por su sentido de modernidad; exalta nobles principios éticos. Creemos que, conjuntamente con la acumulación de conocimiento relativo al Budismo, los latinoamericanos debemos esforzarnos, con sumo empeño, por poner ese conocimiento al servicio de un objetivo humanístico: el enriquecimiento, refinamiento y perfeccionamiento de la persona humana, para bien y felicidad de la misma persona y, a través de ella, para bien y felicidad de la sociedad a que ella pertenece.

No queremos decir con lo anterior que el Budismo no haya sidb utilizado ya en el Japón, en Europa, en Estados Unidos, con fines humanísticos. Pero para los latinoamericanos hacerlo es una necesidad de suma urgencia. La cultura del hambre latinoamericano está en plena etapa de formación. Se están integrando en ella elementos provenientes de Erropa, de Estados Unidos de Norteamérica, de Japón, de la India y, venciendo inexplicables resistencias, elementos de las allturas indígenas, tan cruelmente sofocadas. El Budismo puede contribuir a esa síntesis aportando también elementos positivos. Queremos, como aspiración lejana, difícil de realizar, que la cultura latinomericana se distinga por su riqueza, variedad y alto nivel, por el sentimiento de justicia y solidaridad, por su sentidb de tolerancia y compasión. El Budismo puede colaborar en esta obra, hacer a ella un aporte valioso de elementos nuevos y de elementos que incrementan la eficacia de elementos provenientes de otras fuentes.

\section{Aportes del Budismo}

Cabe preguntar: ¿qué puede aportar el Budismo a la formación cultural del hombre y la mujer latinoamericanos? Daremos algunos ejemplos de los aportes que el Budismo nos puede hacer.

Digamos en principio lo siguiente: El Budismo puede proporcionar ciertas actitudes que benefician al que las posee; ciertos principios fi losóficos que propician un correcto acercamiento a la realidad y ciertos valores éticos que emoblecen las relaciones humanas. 
Entre las actitudes positivas que el Budismo inculca, una de las más interesantes es aquella expresada por la palabra sánscrita adhimukti.

\section{V.1. Adhimukti: Apertura mental, receptividad}

Adhimukti es una palabra importante en los textos budistas. Su interpretación es objeto de discusión. Tsugunari Kubo (The fundamental Philosohpy of the Lotus Sttra with respect to the Practices of the Boohisattva, Tokyo, Shunjûsha, 1987), acertadamente en nuestra opinión, la interpreta como «apertura mental», «receptividad». Adhimukti es la capacidad de la mente de mantenerse abierta ante un nuevo mensaje, de captarlo, de comprenderlo. Sin esa apertura, captación y comprensión, es imposible adherir a ningún mensaje que nos llega por primera vez, por benéfico y eximio que sea. Lo contrario de la adhimukti es la oclusión mental, que lleva al rechazo a priori de avalquier idea, tesis o doctrina que no se adecue a los esquemas que con anterioridad han tomado posesión de nuestra mente. La adhimukti es una cualidad altamente apreciada en el Boothisattva, que ha avanzado ya en el camino que conduce a la Iluminación. Es la adhimukti la que le permite recibir las cada vez más profundas manifestaciones de la Verdad. La adhimukti es un requisito indispensable para el discípulo que se inicia en la Doctrina, que de tantas formas ha de chocarle por sus audaces novedades.

La adhimukti puede ser llevada del terreno intelectual al terreno de los sentimientos. Puede ser concebida entonces como la capacidad de reaccionar ante estímulos muevos que afecten la sensibilidad, de vivir experiencias no vividas antes, en el terreno de las emociones, en el terreno de la creación artística.

La adhimukti, la capacidad de recibir y asimilar nuevas formas de pensar y sentir, constituye la base de un verdadero humani.smo, que se esfuerza por desarrollar las posibilidades de la personalidad, enriqueciéndola, diversificándola, afinándola. La adhimukti es también la actitud que ineludiblemente debe poseer aquel que quiere conocer el Budismo para tomar de él elementos nuevos que contribuyan a su perfeccionamiento intelectual y emocional. 


\section{V.2. Racionalidad}

Se podría decir que dos actitudes distinguen la concepción budista de la realidad: por un lado una tendencia a atenerse a los datos que nos proporciona la experiencia directa de esa realidady, por otro lado, la tendencia a la parquedad en las hipótesis que sustentan esa concepción. Por ejemplo, la teoría de la causalidad universal (: todo tiene causas) y la de la interdependencia universal (: todas las cosas son interdependientes) son teorías fundamentales del Budismo. Constituyen los aspectos más importantes de la doctrina del pratîtyasamutpâda. Ambas teorías están construidas sobre datos proporcionados por una percepción directa de lo que ocurre en nuestra realidad inmediata. De la misma manera, la teoría de los charmas viene a ser un inventario, volcado en sistema, de todo aquello que existe en la realidad y que es captado por nuestros sentidos y nuestra mente. Las dos indicadas tendencias caracterizan también la doctrina de las tres marcas de todo lo existente: transitoriedad, sufrimiento, insustancialidad. Todas estas teorías tienen así una base empírica, lo cual elimina la intromisión de elementos provenientes del mito, de la magia o de creencias preexistentes, transmitidas por la tradición y de inspiración religiosa. Y son las dos actitudes, atenerse a los hechos constatables y la parquedad en la infraestnuctura hipotética, las que le dan a la concepción budista de la realidad el matiz de racionalidad.

Los Brâhmanas y las Upanishads. La racionalidad del Budismo sustentada en las dos actitudes indicadas se toma más evidente si la comparamos con los sistemas filosóficos que inmediatamente lo precedieron o le fueron contemporáneos.

Pensemos en los Brâhmanas. Encontramos en ellos una irrestricta tendencia a personificar, a animar, a hacer actuar como seres rudimentariamente vivos y oscuramente conscientes a todas las cosas imaginables, ya sea que existan concretamente, ya sea que se trate de meras entidades abstractas: plantas, himnos, versos, utensilios litúrgicos, divisiones del tiempo, regiones del espacio, procesos psicológicos. Al lado de estas personificaciones se hacen presentes los dioses heredados del pasado. Luego, a este abigarrado elenco de heterogéneo origen se le hace intervenir en mil hechos diversos, dramas o comedias, en que los personajes se acoplan entre sí, huyen, se 
destruyen, se transforman, se identifican. Todo este mundo de seres y de eventos está al margen de la realidad, de sus leyes, de sus posibilidades; sólo obedecen a la voluntad de los autores de los Brâhmanas, guiada por una loca fantasía o por una lógica que se nos escapa o por una lógica aplicada a la fantasía que nos desconcierta. Y son estas personificaciones y los hechos en que ellas intervienen los que explican el origen y quehacer del mundo, de los dioses, de los hombres. Y, actuando como mitos, le fijan las normas y las leyes a la conducta de los seres.

Pasemos a las Upanishads. Aquí nos encontramos con la postulación de dos principios últimos cuyo conocimiento no deriva de la experiencia ordinaria, pues de entrada se nos dice que no pueden ser conocidos ni por los sentidos ni por la razón y que están más allá de la palabra: Brahman y Âtman Además, nos encontramos en las Upanishads con una proliferación de caprichosas afirmaciones acerca de Brahman y Âtman referidas a sus relaciones con otras entidades (como por ejemplo los alientos vitales) , a los procesos en que participan, a su identificación con otros seres y cosas. Estas afimaciones nos recuerdan, debido a sus contradicciones e incoherencias, aquellas de los Brâhmanas por su contenido y por su inspiración. No es posible estructurarlas en un sistema simple, armonioso y coherente.

Pero lo que más recelo inspira es el origen de ambas nociones. Brahman designó originalmente a la fórmula ritual mágico-religiosa; Âtman designó al aliento vital, es decir la respiración. Ia fómula ritual y el aliento vital son datos que la realidad nos proporciona. Pero los brahmanes, autores de los Brâhmanas y de las Upanishads, especularon sobre la fórmula y el aliento, les fueron atribuyendo cualidades y atributos cada vez más excelsos y en un in crescendo asombroso terminaron por convertir la fórmula ritual en lo Absoluto y la respiración en el Principio Espiritual Individual. Se puede aceptar la existencia de la fórmula litúrgica y del aire que ingresa a muestros pulmones y sale de. ellos; más difícil es aceptar la existencia de aquellos principios supremos en que ambas cosas se convirtieron mediante la metamorfosis de la especulación sacerdbtal: el Absoluto y el Espíritu Individual. Y lo que se dice de esas das principios constituye la concepción de la realidad de los textos upanishádicos. 


\section{V.3. Tolerancia}

Es otra actitud budista. El tolerante permite a otros tener otras ideas diferentes de las suyas y además creer que esas ideas son las mejores y las verdaderas. Ia intolerancia recorta la libertad individual al someterlo a uno a una idea que le impone una forma determinada de pensar, de sentir y de actuar. La intolerancia va casi siempre acompañada de agresividad. Agresividad oral, manifestada en las palabras rudas dirigidas contra los que no piensan como uno; agresividad mental, encerrada en los sentimientos de malevolencia, ira, desprecio, desvalorización contra los que tienen ideas diversas a las de uno; agresividad en los actos violentos destinados a impedir la expresión de ideas diferentes, a lograr por cualquier medio que dejen de existir y aún a destruir a quien los sustenta. Buda decía que las lágrimas derramadas por los hombres durante sus reencarnaciones superaba el agua de varios océanos; podríamos decir en forma similar que también supera al agua de muchos océanos la sangre derramada por actos inspirados en la intolerancia: guerras de religión, conversiones forzosas, persecuciones ideológicas.

Buda recomendaba a sus discípulos actuar con moderación: «Uno debe conocer lo que es la aprobación, uno debe conocer lo que es la desaprobación; conociendo lo que es la aprobación y conociendo lo que es la desaprobación, uno no debe ni aprobar ni desaprobar -uno debe simplemente enseñar el Dharma».

Una idea similar inspira al Emperador Ashoka en el Edicto XII sobre roca. Expresa ahí que la raíz para el progreso esencial de las sectas es el control del lenguaje: uno no debe exaltar a la propia secta y criticar a las otras; si debe por alguna razón hacerlo, debe ser en forma moderada. Más aún, se debe incluso honrar a las otras sectas en una manera u otra.

El Budismo tenía que ser necesariamente tolerante. Su posición esencial adversa a la violencia le impedía adoptar una actitud de intolerancia, acompañada, como dijimos, casi siempre por un espíritu de agresividad.

Contribuyó a la tolerancia budista la conciencia de que la verdad tiene múltiples aspectos o facetas y que por lo general el hombre sólo 
percibe uno de esos aspectos, se aferra a él y, por defenderlo como único existente, adopta actitudes violentas. Ell thera Suhemanta declara en Theragâthâ 106 que todo tiene múltiples características y marcas, que. el necio (dummedha) sólo ve una de ellas y el sabio (pandita) todas. Y el Udâna VI, 4, que narra la conocida historia de los ciegos y el elefante, es una crítica de los que ven sólo una parte de la realidad y violentamente sostienen que es la única.

Corroboró esa actitud relativista la doctrina de las dos verdades: la relativa y la absoluta. Puesto que el hombre normalmente sólo puede llegar a la verdad relativa, que no corresponde a la real naturaleza de las cosas, que es incompleta, provisoria y superable, es insensato adherir a ella como si fuera la verdad absoluta.

\section{Principios filosóficos del Budismo y formación humanista}

\section{VI.1. La causalidad universal}

En el campo de los principios, el principio más importante que el Budismo puede aportar a una formación humanística es la idea del Surgimiento Condicionado o Surgimiento en Dependencia: paticcasamuppâda / pratîtyasamutpâda (en pâli y en sánscrito respectivamente) .

Ia teoría del Surgimiento Condicionado ha sido siempre una teoría fundamental del Budismo. Buda la considera su Dhamma (o Dharma, en sánscrito) (Doctrina) por excelencia. Dice de ella que es el ariyo ñâyo: el Noble Método Budista (Samyutta Mikâya V, Pathamabhayaverûpasantasutta, pp. 338-389, PTS). Muchos textos expresan que Buda descubrió. la teoría del pratityasamutpâda en la guardia media de la noche en que alcanzó la Iluminación -el momento más significativo de la vida de Buda. Buda califica a esa teoría de «profunda» (gambhîra). Y numerosos textos budistas hacen del Surgimiento Condicionado el tema de sus exposiciones.

De acuerdo con esta teoría, toob lo que existe está bajo el dominio de la ley de la causalidad, condensada en la bien conocida fórmula: asmin sati idam bhavatà. «dado esto, se produce aquello». Nada ocurre en el ámbito de la existencia al azar, casualmente. Todo sin excepción 
es el producto de la conjunción de una multiplicidad de causas y condiciones determinantes. Nada surge a la existencia, permanece en ella o sale de ella sin la intervención de múltiples factores causales. Ia universalidad de la ley de la causalidad está expresada en numerosos textos. Además, una de las tres características universales (tilakkhana / trilaksana) de lo existente es la insustancialidad (sabbamanattâ, Samyutta Nikâya IV, Aniccâdisuttanavaka, p. 28) , y toob es insustancial precisamente porque todo es surgido en dependencia (paticcasamuppanna / pratîtyasamutpanna).

\section{2. La interdependencia universal}

La estricta causalidad, que gobiema la realidad empírica en su totalidad, tiene, como corolario, la interdependencia de todo lo que existe, ya que toda cosa es producida, como efecto, por la conjunción de una multiplicidad de otras cosas, que actúan como causas; y consecuentemente cada una de las cosas que actúan como causas es a su vez producida, como efecto, por la conjunción de una multiplicidad de otras cosas, que también actúan como causas; y así en un proceso hacia atrás sin comienzo. Un proceso similar tiene lugar en relación con los efectos. Cada cosa que es producida como efecto, actuando a su vez como causa, en conjunción con una multiplicidad de otras cosas, que también actúan como causas, produce otras cosas; y así en un proceso hacia adelante sin fin.

El resultado de esta interdependencia de causas y efectos, que compenetra la entera realidad, es una «red» que relaciona entre sí todas las cosas existentes -momentáneas, evanescentes, interconectadas por relaciones causales, actuando todas al mismo tiempo como causas y como efectos.

La interdependencia universal es otra gran ley de la existencia.

\section{3. La interdependencia universal y la actualidad}

Siempre se ha sabido que el hombre tiene innumerables dependencias. Cada generación depende de las generaciones precedentes, hereda sus posesiones, se beneficia con su trabajo, sus 
descubrimientos, sus luchas y sus sufrimientos, su experiencia. A su vez cada hombre ha dependido de sus padres para llegar a la vida y sobrevivir, ha dependido de sus maestros para desarrollarse, depende de otros hombres para vivir. Y todos dependemos del aire, del sol para el trabajo, de la noche para el descanso. Pero, ahora, con la superpoblación, con el desarrollo de la industria, del comercio, de la técnica, con los efectos desastrosos que todos esos factores sabemos que pueden producir, se ha tomado conciencia de que todo está relacionado entre sí, es mutuamente dependiente, y de que, por lo tanto, lo que afecte a una parte de ese todo puede afectar no sólo a otras partes, sino al mismo todo, y no sólo a lo existente en el momento en que el hecho se produce, sino incluso a lo que está por existir.

\section{Valores éticos del Budismo}

Pero la conciencia de la interdependencia universal, no basta. Se puede saber que una acción realizada por uno en interés propio produce daños a otros y no preocuparse por ello, por sentirse uno al margen de esas consecuencias dañinas, por pensar que el daño que se producirá en el futuro nada tiene que hacer con uno, por no importarle a uno el daño que a otros se les produzca. No basta la conciencia de la interdependencia universal de seres y cosas; es necesario que junto con esa conciencia se dé en uno la voluntad de no hacer daño (ahimsâ) a otros seres contemporáneos y futuros. La conciencia de la interdependencia universal, sólo cuando va acompañada de esa voluntad de no dañar, puede evitar la realización de acciones que, aunque benefician a unos, pueden perjudicar a otros en el presente o en el futuro. Las formas de perjudicar a otros varían con el curso del tiempo. En nuestros días el número de maneras de hacer daño a los demás seres, contemporáneos y/o futuros, se ha incrementado notablemente, y la magnitud del daño que se puede hacer ha crecido en la misma proporción.

Pero la norma pasiva de no hacer daño a otros no está sola en el Budismo; se le asocia la norma activa de desear el bien de los otros, de hacerles el bien. 
Estas dos normas, no hacer daño y hacer el bien, son normas esenciales del Budismo, que caracterizan la Ética Budista. Podemos designar a ambas con un solo nombre: solidaridad. Ambas normas configuran una Ética de la solidaridad basada en última instancia en la conciencia de la universal interdependencia de todo-seres humanos, animales, plantas, la naturaleza no consciente, las cosas.

Las actitudes de apertura mental, racionalidad y tolerancia, los principios de la causalidade interdependencia universales y el valor de la solidaridad pueden constituir algumos de los aportes del Budismo a la formación del hombre y de la mujer latinoamericanos.

\section{VII.1. Complementariedad ética del conocer por el conocer y de la función hmenistica}

Veamos en algumos ejemplos de qué modo en el estudio del Budismo ambas actitudes, la de conocer por conocer y la de la aspiración a una formación humanística, pueden de hecho conjugarse.

1. Tomemos por ejemplo el caso del arte budista. Cuando estudiamos una pieza de arte budista, debemos, desde luego, describirla técnicamente, señalando el material del cual ha sido hecha, sus medidas, lugar donde fue realizada, dónde fue encontrada, la escuela a la que pertenece, su estilo, las influencias que revela, la concepción doctrinaria budista a la que debe su inspiración.

Pero también podemos promover, educar y cultivar en nosotros la sensibilidad para captar el mensaje estético que esa obra budista transmite, y gozar con ella, de la misma manera como podemos captar el mensaje estético de una obra griega o medieval o moderna y gozar con esa obra. La ampliación de las posibilidades del goce estético constituirá un enriquecimiento de la personalidad, un caso de adhimukti:

2. El caso de los textos y de su contenido es similar, aunque más complejo. Los textos budistas nos darán la ocasión de (a) un estudio lingüístico y (b) un estudio filológico de los mismos.

(a) Enfocándolos lingüŕsticamente, debemos estudiar el idioma en que cada texto está escrito, determinar sus rasgas, fijar sus relaciones con el idioma de otros textos, rastrear su historia a través del tiempo, señalar sus transformaciones, su evolución. Debemos también 
ocuparnos de fijar el valor lo más exacto posible de las palabras de que dispone, en especial de sus términos técnicos, sus matices, sus conexiones fonéticas, morfológicas y semánticas con otros términos. Es un estudio que puede resultar apasionante. El interés suscitado por el idioma en sí puede ser tan intenso que incluso uno puede caer en la actitud negativa de pasar por alto lo que el texto nos expresa. Tal es el caso del profesor británico K.R. Noman, autor de una impresionante colección de rigurosos artículos sobre el idioma pâli, en que está compuesta la ensefianza que durante más de 20 siglos ha constituido la inspiración espiritual de millones de seres. Ell profesor Noman con encomiable franqueza nos dice: «Yo no soy un scholar del Budismo, y debo confesar que no tengo gran interés en el tema, y conozco poco o nada acerca de él' («Pâli Philology and the Study of Budbhi.sm», en The Buablhist Form, Vol. I; London, University of London, 1990, p. 38).

(b) El enfoque filológico del texto es igualmente imprescindible. Los textos budistas nos han llegado mediante una transmisión de muchos siglos en diversos idiomas. No podemos ignorar la historia de esa transmisión, la forma como se efectuó la preservación de los textos, sus variadas recensiones, los criterios a que debemos sometemos ante divergencias en esas recensiones. Debemos establecer ediciones confiables, producto de una labor crítica; ediciones que nos proporcionen el texto que analizamos en la forma más cercana a la época en que fue compuesto, y nos suministren los elementos para establecer las alteraciones, cambios, modificaciones que experimentó en el arrso de los siglos.

3. Provistos de las bases lingüŕsticas y filológicas ineludiblemente necesarias, podemos abordar la tarea de establecer de una manera científica lo que el texto dice: hacer la descripción de las ideas, tesis, normas que transmite, inventariar su contenido, determinar las relaciones de este contenido con el de otros textos, descubrir las fuentes de las ideas que sostiene, los factores que a éstas les dieron origen, su ubicación en la evolución del pensamiento en que se insertan, sus transformaciones, su sobrevivencia.

El estudio del idioma que se limita exclusivamente al conocimiento del idioma, la labor filológica encerrada en sí misma, y el mero análisis del contenido doctrinario del texto ponen ante nosotros multitud de 
hechos y datos, satisfacen el ansia de conocer por conocer, constituyen el ideal del bahurinutîya de la India, del polymathés griego, del erudito moderno.

Las tres indicadas tareas con relación a los textos son actividades altamente valiosas, en cuanto incrementan el conocimiento en sí y son imprescindibles para un estudio serio y científico del Budismo.

Pero, pensamos que, junto con ellas, complementándolas, puede el estudio del Budismo aspirar a llenar otra función más: la función humanística, que en el caso de nosotros los latinoamericanos no sólo es conveniente, sino incluso indispensable.

Creemos que el trato con los textos budistas y el estudio de las doctrinas que contienen pueden suscitar en nosotros una tendencia hacia las explicaciones racionales caracterizadas por la voluntad de atenerse a los hechos y por la parquedad en las hipótesis explicativas. Esta actitud nos ayudará a no adherir a construcciones teóricas no sustentadas en hechos, a ser conscientes de las creencias y dogmas que cada cultura subrepticiamente impone a sus miembros en todos los terrenos del quehacer humano, a ser muy cautos respecto de esas creencias y dogmas, a no convalidarlas con el apelativo de «misterios» a los que no llegan ni nuestros sentidos ni nuestra razón, y que precisamente por eso son dignos de crédito y respeto. Nos ayudará a erradicar de nosotros aquella cupido obscura credendi, aquel «deseo de creer en las cosas ascuras», que hace 20 siglos el más grande historiador latino, Tácito (Historiae I, XXII), consideraba ínsito en la naturaleza humana.

Un sentimiento de tolerancia será otro de los beneficios derivados del estudio de los textos budistas: dejar que los otros crean, piensen, sientan libremente, no doligados a creer, pensar y sentir como nosotros lo hacemos. La tolerancia nos liberará de la agresividad, que puede manifestarse desde el desprecio y la humillación hasta la violencia y la destrucción. Además contrarrestará una proclividad muy común en aquellos que nos dedicamos al estudio de las culturas orientales. Con el sentimiento de nuestra superioridad cristiano-occidental, con la creencia de que somos «hijos de la razón» y de que estamos signados por la moderación, juzgamos despectivamente y repudiamos severamente, como irracionales e inmoderadas, muchas creencias y 
doctrinas de esas culturas. La intolerancia y la agresividad derivada de ella nos impiden percibir que en nuestra propia cultura existe un cúmulo de creencias y doctrinas tan irracionales, tan irmoderadas como aquellas de otras culturas que son objeto de nuestro indignado rechazo. Nuestras propias irracionalidades las hemos absorbido con nuestra educación y no las percibimos, ocultas como están por los velos de nuestro prejuicios y de nuestro orgullo; las ajenas aparecen ante nosotros en todo su repudiable esplendor. Un ejemplo de la anterior limitación nos la ofrece el gran budólogo belga Louis de la Vallée Poussin, muy vinculado con el Catolicismo belga. En una conferencia sustentada en Cambridge en 1916 se expresó de la siguiente manera en relación al pensamiento y pensadores de la India: «Ell historiador no trata con nociones latinas creadas por pensadores sobrios y de clara visión, sino con «philosophumena» indios inventados por ascetas a quienes describiremos camo hombres agotados por una severa dieta y frecuentemente idiotizadbs por la práctica del éxtasis. Ios indios no hacen una clara distinción entre hechos e idkas, entre ideas y palabras; nunca han reconocidb claramente el principio de contradicción» (The Wray to Nivâna, Cambridge, 1917, p. 111). De la Vallée Poussin no recordaba, cuando escribía estas líneas, que la filosofía occidental, desde Grecia hasta nuestros días, también ostenta una gran riqueza de «philosophumena» oscuros, abstrusos, incoherentes e irracionales, que los místicos occidentales también sufrieron muchos de ellos de desmutrición ascética y tuvieron serias dolencias nerviosas, que los hicieron calificar clínicamente como enfermos de histeria y que muchos confundían ilusiones o alucinaciones con la realidad. Y de la Vallée Poussin no podía, con un trazado de pluma, despojar a los indios, entre ellos los grandes lógicos hindúes y budistas, del uso de la razón, convirtiendo a ésta en patrimonio exclusivo de Occidente. La tolerancia traerá consigo una actitud más científica ya que no permitirá que muestros sentimientos y emociones se mezclen con nuestros juicios críticos, influyan en ellos, los hagan sospechosas de parcialidad. Y la tolerancia también nos permitirá descubrir en las doctrinas de otras culturas, junto con los elementos irracionales e inmoderados que en ellas puedan darse, otros elementos positivos, valiosos, interesantes, dignos de respeto y admiración intelectuales. 
Finalmente, procuraremos hacer nuestra la idea de la causalidad universal: todo es efecto de causas y todo es causa de efectos, y todo está interconectado, es interdependiente; y, conjuntamente, procuraremos inspirar nuestra conducta en un sentimiento de solidaridad o de compasión (kânma) universal, que nos impulse a no hacer daño; a hacer el bien a otros. En Latinoamérica (como por lo demás en el resto del mundo) hay mucha pobreza, miseria, ignorancia, angustia. Un sentimiento de solidaridad debería inducimos a percibirlas, a no ignorarlas y a tratar, de acuerdo con nuestras fuerzas, de aliviar esos factores negativos, de hacerlos desaparecer. No es sólo una abligación religiosa o moral; es una dbligación cultural. Ell concepto de cultura varía con el tiempo y la evolución social. Se van integrando en ella nuevos requisitos, que la tornan más rica y compleja. La percepción de la interdependencia universal entre todos los seres y cosas, el sentimiento de solidaridad, el rechazo de la violencia y de la crueldad, la voluntad de ayudar, son elementos que están pasando a formar parte de la noción de cultura, bajo la influencia de un mayor refinamiento de los sentimientos y del pensamiento y también debido a la intuición de los peligros que corre la especie humana justamente por no tomar en cuenta esas muevas exigencias de lo que es la cultura.

A suscitar, promover o corroborar esos sentimientos y actitudes puede colaborar eficazmente el estudio del Budismo, que tuvo como núcleo de su enseñanza la vivencia del dolor humano y como aspiración la felicidad de todos los hombres:

sabbe sattâ bhavantu sukhitattâ

«que todas los seres sean felices». 